\title{
Asymmetric Evolutionary Game Analysis of Building Information Modeling (BIM) Technology Diffusion
}

\author{
Qian Liu (D) \\ CCCC Fourth Highway Engineering Co. Ltd., Beijing 100022, China \\ Correspondence should be addressed to Qian Liu; qianliang33152@163.com
}

Received 22 October 2021; Accepted 26 November 2021; Published 29 December 2021

Academic Editor: Lingkun Chen

Copyright ( 2021 Qian Liu. This is an open access article distributed under the Creative Commons Attribution License, which permits unrestricted use, distribution, and reproduction in any medium, provided the original work is properly cited.

\begin{abstract}
Building Information Modeling (BIM) technology plays a pivotal role in the process of building process informatization. In the context of extensive promotion by all parties, how to effectively evaluate the promotion value of countries and enterprises is particularly important. In order to better analyze the promotion trend of the BIM technology diffusion system in China, a noncooperative evolutionary game model of BIM technology diffusion between the government and enterprises is constructed, and Vensim PLE software is used for simulation analysis in this paper. The model includes government subsidy cost and penalty, social benefit and loss, and income payment matrix of BIM technology input income and cost. The results show that enterprises need not only direct cost subsidy from the government but also indirect cost subsidy in the process of BIM technology diffusion. Appropriate government penalties can effectively promote the initiative of enterprises to adopt BIM technology; BIM has a great impact on the input income and cost of enterprises. In view of this, it is suggested that the first task for enterprises to promote the diffusion of BIM technology is to clarify the definition of BIM's high investment cost and do a good financial impact analysis.
\end{abstract}

\section{Introduction}

Building Information Modeling (BIM) is generally understood as a general term describing various activities of objects in computer-aided design (CAD), which supports the use of $3 \mathrm{D}$ geometric and nongeometric functional attributes and relationships to represent architectural elements and describe the characteristics of the object in 3D. Therefore, BIM is considered a series of technologies and solutions [1]. The diffusion of BIM technology can solve the technical problems in the process of engineering construction, strengthen the collaborative work among organizations, promote the efficiency of engineering construction, increase productivity, and improve and optimize design, construction, and maintenance of construction products. At present, China's formulation of the "Building Information Model Construction Application Standards" and the new policies issued by most provinces and cities where "BIM technology is required for large public buildings of more than 20,000 square meters" have all promoted the application of BIM technology in China to a certain extent. However, there are no mandatory regulations for private investment construction projects, and the lack of BIM consulting agencies, the constraints of BIM maturity, deeprooted traditional construction ideas, and a series of problems caused by information asymmetry have greatly hindered China's BIM proliferation of technology. At the same time, as a low-carbon environment-friendly technology, BIM technology's diffusion quality and efficiency [2] are of great significance for sustainable development and are also the focus of attention of scholars at home and abroad [3].

Diffusion is a process in which individuals, societies, or organizations adopt innovation over a period of time [4]; it is generally believed that technology diffusion is a social phenomenon [5]. Chen et al. [6] extended technology diffusion research to the organizational environment and introduced factors such as critical quality and knowledge barriers. Grover et al. [7] combined Twitter analysis and academic literature analysis to provide better diffusion insights for the diffusion of blockchain technology than a single data source. As a cross-organization collaboration 
technology, BIM is not aware of the application value of BIM, and the value-added effect brought by BIM application [8] is considered to be the key factor restricting the diffusion and development of BIM in China. The market behavior of enterprises is the essence of technology diffusion, and government departments play a leading role [9]. The proliferation of BIM technology cannot rely solely on government policies but, more importantly, the independent choice of enterprises. The adoption of BIM technology by enterprises requires payment of the huge cost of the BIM technology system, and if enterprises want to gain a costleading advantage, then enterprises should focus on innovative activities that minimize costs [10]. Some scholars use the DOI method to explain the spread of BIM within organizations $[11,12]$ and the spread of BIM in the industry [13]. Reference [14] used a set of diffusion factors determined by Peansupap and Walker (V. Peansupap and D. H. T. Walker, 2005) to study the diffusion of BIM. Ma et al. [15] applied evolutionary game theory to the research of industrial common technology diffusion model and analyzed the main behavior and influence mechanism of technology diffusion in different evolution stages. Laciana and Rovere [16] found that the behavior of early adopters of technology had the most significant impact on the speed of technology diffusion by simulating the dynamic process of technology diffusion. The diffusion of BIM technology in the construction industry is still in the early adopter stage of technology adoption, and the overall diffusion rate is still very slow [17]. Sun et al. [18], based on the agent model and evolutionary game theory, simulated the technology diffusion under different relationships. The above research provides ideas and enlightenment for constructing the BIM technology diffusion model in this paper [15, 19-30].

At present, academic research on the diffusion of BIM mostly focuses on diffusion factors, barriers, and diffusion in the entire technical field. However, there are few research results on the diffusion of BIM technology. Existing research mainly includes the description of the current status of BIM diffusion and the factors affecting the diffusion identification, driving the proliferation strategy. In addition, China adheres to the basic principle of "enterprise dominance, industry services, and policy promotion" for the diffusion of BIM technology [31]. However, few existing studies consider the diffusion of BIM technology from the perspective of government and enterprises. In view of this, this article uses evolutionary game theory to establish the BIM technology diffusion evolution game model based on the analysis of the relationship between the game subjects of the building information model (BIM) technology diffusion and analyzes the evolution process of government and enterprise behavior during the BIM technology diffusion process. And the evolutionary stability strategy, through numerical simulation, analyzes the influence of government reward and punishment system, enterprise risk attitude, and other factors on government and enterprise strategy choices, so as to put forward policies and suggestions to promote the diffusion of BIM technology in China.

\section{Analysis of Game Subject Relationship of BIM Technology Diffusion}

The process of technology diffusion is a game process, and the decisions made by the participants will not only consider their own interests but also consider the impact of the decision on other participants [32]. However, in the process of BIM technology diffusion, due to the asymmetry of information among the participating entities, the imperfection of BIM related standards, norms, and laws, and the inequality of the benefits of applying BIM technology (the biggest beneficiary of applying BIM technology is units, followed by construction units, design units, etc.) and the huge differentiation of BIM investment (the largest investor investing in BIM technology is the construction unit, followed by the design unit, construction unit, etc.), making it difficult for BIM to pass the mutual interaction between them realizes the widespread adoption and application of BIM technology. Therefore, to achieve the full spread of BIM technology, enterprise adoption is a prerequisite, and the government's active promotion is a necessary means [33]. The proliferation of BIM technology has accelerated, and the government will reap regulatory costs for quality, safety, environmental protection, and waste of resources. The influence of government agencies on the spread of BIM technology is mainly reflected in accelerating the adoption of BIM application enterprises through regulations, policies, guidelines, and other measures, by calling on local governments to actively promote the application of BIM technology, and training major qualified enterprises to learn BIM knowledge through the organization with skills, etc. In order to implement the government's policy requirements, enterprises will also face pressures from insufficient investment funds, shortage of BIM comprehensive talents, difficulty in project management, and poor adaptability of management personnel. At the same time, the entire set of optimization programs in BIM technology has changed the traditional construction industry. The current situation of high energy consumption, high danger, many quality accidents, slow progress, low efficiency, and poor personnel coordination also allows enterprises to effectively control investment, progress, quality, safety, environmental protection, etc. and ultimately achieve huge project success income.

It can be seen from the prospect theory $[34,35]$ that individual strategy choice preferences depend on their individual subjective psychological feelings when gaining and losing strategies and are manifested as loss aversion. Therefore, BIM application companies are confronted with the high cost of adoption and government guarantees. Insufficient, unclear, or obvious benefits, lack of successful implementation cases, etc. often adopt a risk avoidance strategy and put themselves in a wait-and-see state; the government is facing the high R\&D costs of BIM and the current status of traditional construction methods. And under the circumstance that enterprises are not enthusiastic about independent research and development and adoption, 
the government tends to adopt a conservative strategy, mostly based on encouraging policies, and the most intuitive performance is that there are few subsidies to enterprises. At the same time, due to the slow diffusion of BIM in China, there are still many obstacles in the application of BIM in technology, management, law, contracts, etc. As a limited rational person, the government and enterprises are cautious in the strategy selection process. Therefore, the diffusion process of BIM technology is still very slow, and it will take a long time to diffuse in the entire construction industry, and it is necessary to explore effective ways to accelerate the diffusion of BIM technology in China.

\section{Evolutionary Game Analysis of BIM Technology Diffusion}

The evolutionary game model is mainly established on the basis of mutation mechanisms and selection mechanisms. In the process of BIM technology adoption, the selection mechanism refers to the strategy that the government and enterprises can obtain higher benefits at the current stage, which will be adopted by more players through learning and imitation in the next stage; mutation refers to the fact that some participants in the adoption of BIM technology choose strategies in a random manner, so the mutation strategy may get lower gains or higher gains. The former will become popular after selection, and the latter will naturally go away. The essence of BIM technology diffusion is a process of the multisubject mutual game, which belongs to the evolutionary game model with social strategy changes. The strategic combination of the game subject through adaptive adjustment and continuous evolution, that is, the "good"" strategy becomes more popular [36], thus providing reference and reference for the choice of gamers strategy.

\subsection{Evolutionary Game Model Construction}

Hypothesis 1. There are two completely different limited rational groups in the BIM technology diffusion system: BIM application companies (including construction units, design units, construction units, operating units, and consulting units) and government agencies (departments representing government agencies, associations, etc.). The strategies that the government can choose are actively promote; passively promote\}, the strategies that the enterprise can choose are actively adopt BIM technology; passively adopt BIM technology\}, and the two parties will form an evolutionarily stable strategy through the dynamic repeated game. Probability of government strategy choice $=\{$ probability of positive advancement, probability of negative advancement $\}=\{\alpha, 1-\alpha\}$, and probability of enterprise strategy choice $=\{$ probability of actively adopting BIM technology, probability of passively adopting BIM technology $\}=\{\beta, 1-\beta\}$, where $\alpha, \beta \in[0,1]$ are all functions of time $t$.

Hypothesis 2. The government is the main body of market supervision, and the enterprise is the most important body in the market. The two companies have different total benefits in the process of BIM technology diffusion. Enterprises tend to pay more attention to economic benefits, while the government pays more attention to BIM technology. Social benefits are brought by diffusion. Use $R$ to indicate that the government actively promotes the social benefits brought by the diffusion of BIM technology, and use $B$ and $B^{\prime}$, respectively, to indicate the profit before and after the adoption of BIM technology. At the same time, the government and enterprises will also pay a corresponding price. In this paper, the government will actively promote the diffusion of BIM technology and the cost of subsidy management for enterprises will be represented by $C_{1}$ and represents the subsidy coefficient; then, the government subsidy for enterprises will be $\gamma C_{1}$. A series of costs for adopting and using BIM technology is denoted by $C_{2}$; the excess operating costs paid by enterprises for passive adoption are denoted by $G$. At the same time, the government's passive promotion and passive adoption of enterprises will cause a certain social loss $L$, which will be borne by the government.

Hypothesis 3. With the increasing demands on production, economy, and quality, BIM brings a set of organizational solutions for the construction industry to increase productivity. BIM technology can bring core competitiveness to enterprises. Those who have not been adopted or passively adopted BIM technology companies will lose their advantages in the competition in the entire construction market. At the same time, if the government actively promotes BIM technology, enterprises will be punished for choosing passive strategies; if the government passively promotes BIM technology, enterprises will lose the value-added benefits that BIM can bring. Therefore, there are risks of profit and loss in the diffusion of BIM technology. We make the government passively promote the enterprise to adopt the impairment loss value of $D$, and the government actively promotes the passive penalty of the enterprise to be $K$; then, the risk profit and loss values of the two are $D$ and $K$, respectively.

Based on the above assumptions, we construct a revenue payment matrix for both the government and the enterprise (Table 1).

\subsection{Evolutionary Game Stability Strategy Analysis.} According to the income payment matrix of government and enterprises in the process of BIM technology diffusion in Table 1, the profit function of pure strategy and mixed strategy and the dynamic differential equation of replication of the BIM technology diffusion system can be obtained as follows.

The revenue function that the government chooses to actively promote the strategy is

$$
U_{11}=\beta\left(R-C_{1}-\gamma C_{1}\right)+(1-\beta)\left(-C_{1}+K\right) .
$$

The return function of the government's choice of passive promotion strategy is 
TABLE 1: The revenue payment matrix of both the government and the enterprise.

Government

Positive advancement $(\alpha)$

Negative advancement $(1-\alpha)$
The average government revenue is

$$
\bar{U}_{1}=\alpha U_{G 1}+(1-\alpha) U_{G 2} .
$$

From equations (1)-(3), the government's replication dynamic differential equation is

$$
\begin{aligned}
F_{1}(\alpha) & =\frac{d \alpha}{d t}=\alpha\left(U_{11}-\bar{U}_{1}\right)=\alpha(1-\alpha)\left(U_{11}-U_{12}\right) \\
& =\alpha(1-\alpha)\left[-\beta\left(L+\gamma C_{1}+K\right)+K-C_{1}+L\right] .
\end{aligned}
$$

The profit function of an enterprise's choice to actively adopt a strategy is

$$
U_{21}=\alpha\left(B^{\prime}-C_{2}+\gamma C_{1}\right)+(1-\alpha)\left(B^{\prime}-C_{2}-D\right) .
$$

The income function for enterprises to choose passive adoption strategies is

$$
U_{22}=\alpha(B-G-K)+(1-\alpha)(B-G) .
$$

The average expected additional benefit of the enterprise is

$$
\bar{U}_{2}=\beta U_{E 1}+(1-\beta) U_{E 2} .
$$

From equations (5)-(7), the replication dynamic differential equation of an enterprise is

$$
J=\left(\begin{array}{c}
(1-2 \alpha)\left[\beta\left(L+\gamma C_{1}+K\right)-K+C_{1}-L\right] \\
\beta(1-\beta)\left(D+\gamma C_{1}+K\right)
\end{array}\right.
$$

Enterprise

Passively adopting BIM technology $(1-\beta)$ $-L ; B-G$

$$
\begin{aligned}
F_{2}(\beta) & =\frac{d \beta}{\mathrm{d} t}=\beta\left(U_{E 1}-\bar{U}_{E}\right)=\beta(1-\beta)\left(U_{E 1}-U_{E 2}\right) \\
& =\beta(1-\beta)\left[\alpha\left(\gamma C_{1}+D+K\right)-B+G-D-C_{2}+B^{\prime}\right] .
\end{aligned}
$$

From equations (4) and (8), the steady state of the replication dynamics is $(0,0),(0,1),(1,0),(1,1)$, and $\left(\alpha^{*}, \beta^{*}\right)$; among them, $\alpha^{*}=\left(B-G+D+C_{2}-B^{\prime}\right) /\left(\gamma C_{1}+D+K\right)$ and $\beta^{*}=\left(K-C_{1}+L\right) /\left(L+\gamma C_{1}+K\right)$.

One basic concept of evolutionary game theory is the evolutionarily stable strategy (ESS), which means that when all members of a group adopt this strategy; then, under the influence of natural selection, no mutation strategy will invade this group [36]. The traditional game theory is premised on the assumption of rational people, while the evolutionary game theory is based on limited rationality, through adjustment, comparative analysis, learning, and other strategies between two or more players in the game, after many repeated and dynamic long-term games, to find a stable state, that is, the evolutionarily stable strategy between game players. According to the method proposed by Friedman [37], the system's evolutionarily stable strategy (ESS) can be obtained through the local stability of the Jacobian matrix. Therefore, from equations (4) and (8), the Jacobian matrix of the game between the government and the enterprise can be obtained as follows:

According to evolutionary game theory, when $\operatorname{det}(J)>0$ and $\operatorname{tr}(J)<0$, the equilibrium point will approach a local progressive stable state, also known as evolutionary equilibrium state; when $\operatorname{det}(J)>0$ and $\operatorname{tr}(J)>0$, the equilibrium point will not approach the local progressive stable state, that is, in an unstable state; when $\operatorname{det}(J)<0$ and $\operatorname{tr}(J)=0$ or uncertain, the equilibrium point is a saddle point, also. That is, the equilibrium point is stable in one direction and unstable in the other direction. The basis for judging whether the three parties in the game are in an evolutionary equilibrium state is whether $\operatorname{det}(J)>0$ and $\operatorname{tr}(J)<0$ are true. The judgment results are shown in Table 2 . It can be seen from the game theory that when $\operatorname{det}(J)>0$ and $\operatorname{tr}(J)<0$, the equilibrium point will approach a locally asymptotically stable state; that is, it will reach an evolutionary equilibrium state. By calculating the $\operatorname{det}(\boldsymbol{J})$ and $\operatorname{tr}(\boldsymbol{J})$ of the 5 equilibrium points, it can be judged whether the game system has evolved to a stable state. The expressions of the determinant and traces of each equilibrium point are shown in Table 2.

It can be seen from Table 2 that the sizes of $\operatorname{det}(J)$ and $\operatorname{tr}(J)$ corresponding to the equilibrium point and $-B+G-D-C_{2}+B^{\prime}, K--C_{1}+L, \gamma C 1+K--B+G-C 2+B^{\prime}$ are positive and negative related, so the stability of the five equilibrium points is analyzed by considering the size of these three expressions, as follows:

(1) When $-B+G-D-C_{2}+B^{\prime}>0$ and $K--C_{1}+L>0$, that is, when the government chooses to actively promote BIM technology, the net income of the company's active adoption of BIM technology is greater than 0 , and when the company chooses to passively adopt BIM technology, the net income actively promoted is greater than 0 , and the evolutionary stabilization point of the government and 
TABLE 2: $\operatorname{det}(\boldsymbol{J})$ and $\operatorname{tr}(\boldsymbol{J})$ corresponding to the equilibrium point.

\begin{tabular}{lcc}
\hline Equilibrium point & & Determinants and trace expressions \\
\hline$(0,0)$ & $\operatorname{det}(\boldsymbol{J})$ & $\left(-K+C_{1}-L\right)\left(-B+G-D-C_{2}+B^{\prime}\right)$ \\
& $\operatorname{tr}(\boldsymbol{J})$ & $\left(-K+C_{1}-L\right)+\left(-B+G-D-C_{2}+B^{\prime}\right)$ \\
$(0,1)$ & $\operatorname{det}(\boldsymbol{J})$ & $\left(\gamma C_{1}+C_{1}\right)\left[-\left(-B+G-D-C_{2}+B^{\prime}\right)\right]$ \\
& $\operatorname{tr}(\boldsymbol{J})$ & $\left(\gamma C_{1}+C_{1}\right)+\left[-\left(-B+G-D-C_{2}+B^{\prime}\right)\right]$ \\
$(1,0)$ & $\operatorname{det}(\boldsymbol{J})$ & {$\left[-\left(-K+C_{1}-L\right)\right]\left(\gamma C_{1}+K--B+G-C_{2}+B^{\prime}\right)$} \\
& $\operatorname{tr}(\boldsymbol{J})$ & {$\left[-\left(-K+C_{1}-L\right)\right]+\left(\gamma C_{1}+K--B+G-C_{2}+B^{\prime}\right)$} \\
$(1,1)$ & $\operatorname{det}(\boldsymbol{J})$ & {$\left[-\left(\gamma C_{1}+C_{1}\right)\right]\left[-\left(\gamma C_{1}+K--B+G-C_{2}+B^{\prime}\right)\right]$} \\
& $\operatorname{tr}(J)$ & {$\left[-\left(\gamma C_{1}+C_{1}\right)\right]+\left[-\left(\gamma C_{1}+K--B+G-C_{2}+B^{\prime}\right)\right]$} \\
& & {$\left[\left(-B+G-D-C_{2}+B^{\prime}\right)\left(D+\gamma C_{1}+K\right)\right.$} \\
$\left(\alpha^{*}, \beta^{*}\right)$ & $\operatorname{det}(J)$ & $\left.+\left(-B+G-D-C_{2}+B^{\prime}\right)^{2}\right][(K-C 1+$ \\
& & $\left.+L)(L+\gamma C 1+K)-(K-C 1+L)^{2}\right]$ \\
& $\operatorname{tr}(J)$ & $\left(D+\gamma C_{1}+K\right)(L+\gamma C 1+K)$
\end{tabular}

enterprises tends to be $(1,1)$. The evolutionary stabilization strategy is for the government to choose to actively promote BIM technology, and the enterprise chooses to actively adopt BIM technology (Table 3).

(2) When $-B+G-D-C_{2}+B^{\prime}>0, K--C_{1}+L<0$, that is, when the government chooses to actively promote BIM technology, the net income of the company's active adoption of BIM technology is greater than 0 , and when the company chooses to passively adopt BIM technology, the net income actively promoted is less than 0 , and the evolutionary stabilization point of the government and enterprises tends to be $(1,1)$. The evolutionary stabilization strategy is for the government to choose to actively promote BIM technology, and the enterprise chooses to actively adopt BIM technology (Table 3).

(3) When $-B+G-D-C_{2}+B^{\prime}<0, \gamma C 1+K-B+G-C 2$ $+B^{\prime}>0$, and $K-C_{1}+L>0$, that is, when the government chooses to actively promote BIM technology, the net income of BIM technology is less than 0 . When the government chooses to actively promote BIM technology, the net income of enterprises actively adopting BIM technology is greater than 0 . When the company chooses to passively adopt BIM technology, the net income actively promoted by the government chooses to be greater than $0 .(0,0)$ or $(1$, 1): the evolutionary stabilization strategy is that the government chooses to promote passively BIM technology, enterprises choose to passively adopt BIM technology, or the government chooses to actively promote BIM technology, and enterprises choose to actively adopt BIM technology (Table 3).

(4) When $-B+G-D-C_{2}+B^{\prime}<0, \quad \gamma C 1+K--B+G-$ $C 2+B^{\prime}>0$, and $K-C_{1}+L<0$, that is, when the government chooses to actively promote BIM technology, the net income of BIM technology is less than 0 . When the government chooses to actively promote BIM technology, the net income of enterprises actively adopting BIM technology is greater than 0 . When the company chooses to passively adopt BIM technology, the net income actively promoted by the government chooses to be less than
0 . $(1,1)$ : the evolutionary stabilization strategy is actively promoted by the government, and enterprises choose to actively adopt BIM technology (Table 3).

(5) When $-B+G-D-C_{2}+B^{\prime}<0, \gamma C 1+K--B+G-$ $C 2+B^{\prime}<0$, and $K--C_{1}+L>0$, that is, when the government chooses to actively promote BIM technology, the net income of BIM technology is less than 0 . When the government chooses to actively promote BIM technology, the net income of enterprises actively adopting BIM technology is less than 0 . When the company chooses to passively adopt BIM technology, the net income actively promoted by the government chooses to be greater than 0 . $(0,0)$ : the evolutionary stabilization strategy is for the government to choose passive advancement, and enterprises choose to passively adopt BIM technology (Table 3 ).

(6) When $-B+G-D-C_{2}+B^{\prime}<0, \gamma C 1+K-B+G-C 2$ $+B^{\prime}<0$, and $K-C_{1}+L<0$, that is, when the government chooses to actively promote BIM technology, the net income of BIM technology is less than 0 . When the government chooses to actively promote BIM technology, the net income of enterprises actively adopting BIM technology is less than 0 . When the company chooses to passively adopt BIM technology, the net income actively promoted by the government chooses to be less than 0 . $(1,0)$ : the evolutionary stabilization strategy is actively promoted by the government, and enterprises choose to adopt BIM technology passively (Table 3).

According to the above stability analysis results, the strategic dynamic evolution diagram (Figure 1) of the government and enterprises in promoting BIM technology diffusion can be obtained.

\section{Simulation Analysis}

Large real estate companies such as Vanke, Evergrande, Country Garden, and Sunac have played a leading role in the diffusion of BIM technology and have demonstrated the characteristics of high BIM application frequency, wide 


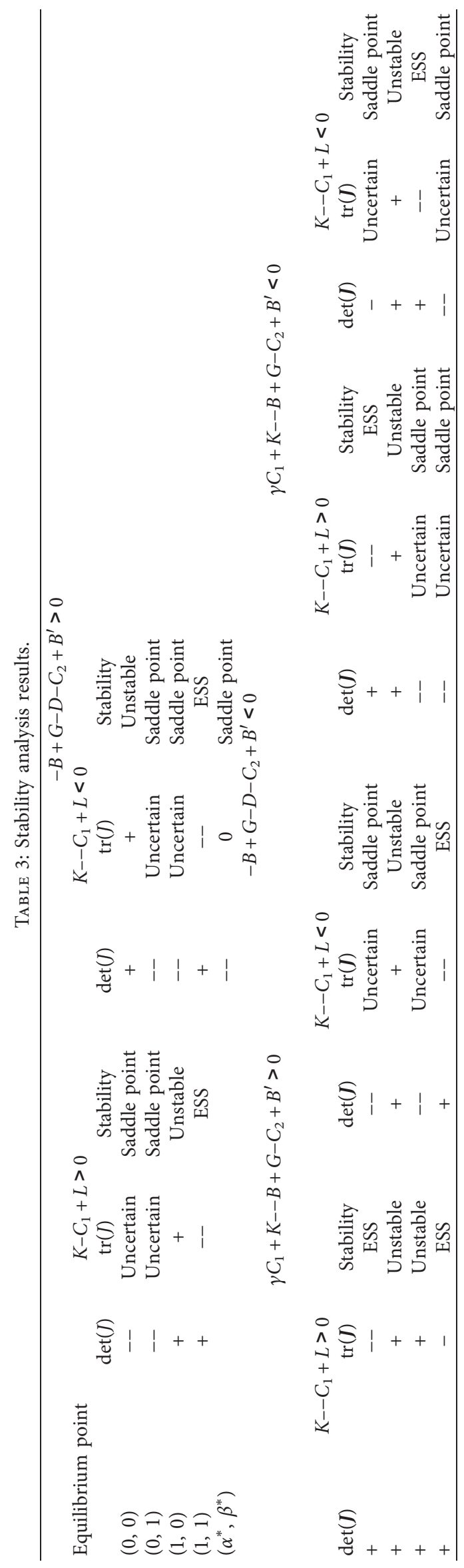




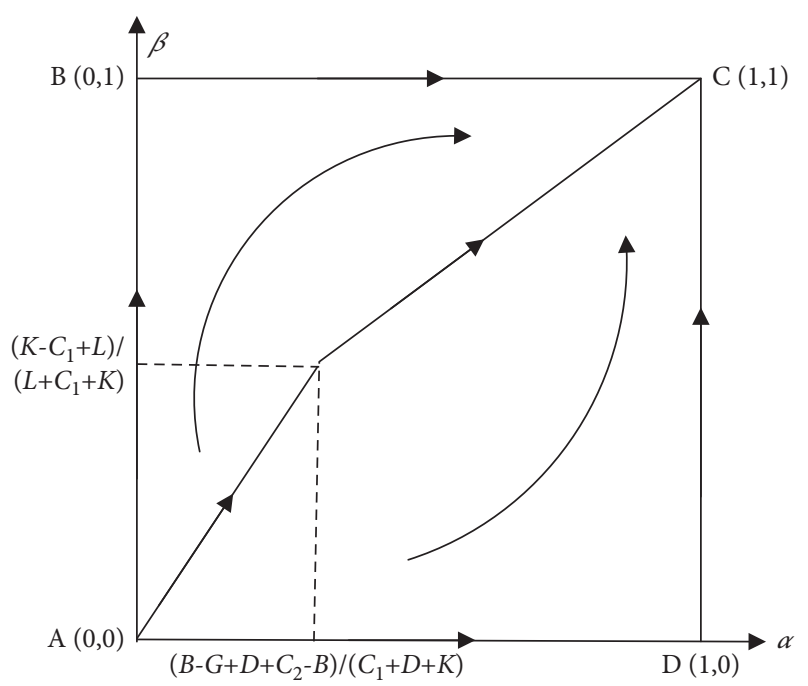

Figure 1: The dynamic evolution of government and enterprise strategy.

application range, and many successful BIM application cases. Accelerating the spread of BIM technology is also constantly improving the BIM standards and norms suitable for China's scenarios and promulgating relevant policies, laws, guidelines, and opinions. In the BIM technology diffusion game model, $K, C_{1}, L, C_{2}, B^{\prime}$, and other parameters affect the strategic choices of the government and enterprises and also affect the evolution process. This article uses the software Vensim PLE (system dynamics software) to simulate the dynamic evolution process that affects the strategic choices of both parties in the diffusion of BIM technology. Vensim PLE type simulation generally follows the following steps: create a new model $\longrightarrow$ check whether the model structure is correct $\longrightarrow$ simulate operation $\longrightarrow$ check whether the model behavior is normally $\longrightarrow$ change the value for simulation test $\longrightarrow$ output the model and its behavior. The focus of system dynamics simulation is the overall system behavior trends and the impact of policy changes. It does not have strict requirements for the accuracy of the results [38]. Yuan Yijun et al. [39] also pointed out that the correctness of the model structure is more important than the choice of parameters. In order to further analyze the strategic relationship between the government and enterprises in the game, we use the assignment method in $[39,40]$, consider that the status quo of China's BIM technology is still in its infancy, and assign parameters to the BIM diffusion system. The assignments are $\alpha=0.6, \beta=0.5, R=16, C_{1}=10, C_{2}=15$, $B=20, B^{\prime}=35, L=7, D=4, K=5, G=6, \gamma=0.5$, simulation period $T=120$, initial time $=0$, final time $=120$, and time step $=0.5$.

(1) The sensitivity analysis of the government and enterprises to the fine $K$ : the parameter $K$ is the penalty that the government actively promotes the passive adoption of enterprises, and it has a certain reference value for the government's policy. Let $K=5,9,20$; the

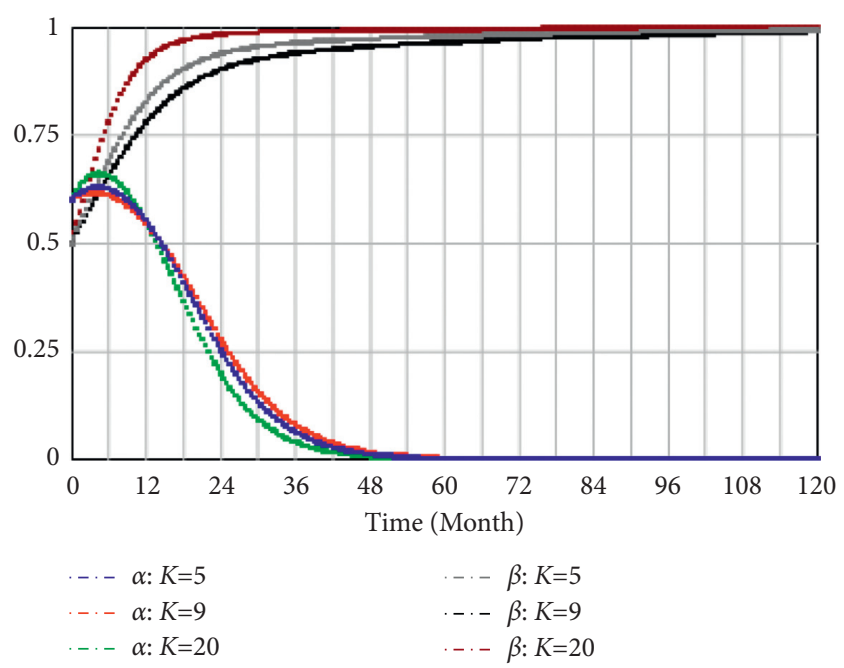

FIGURE 2: The sensitivity analysis of government and enterprises to (K) value.

evolution of the BIM technology diffusion game system is illustrated in Figure 2.

It can be observed from Figure 2 that the spread of BIM technology between the government and enterprises is affected by government fines. When $K=5,9,20$, it is obvious that the government adopts a strategy of actively advancing, and enterprises also choose to actively adopt the strategy. At this time, the BIM technology diffusion game system evolves steadily toward C $(1,1)$. The purpose of the government to impose fines on enterprises is to urge enterprises to actively adopt BIM technology. As can be seen in Figure 2, when the fines continue to increase, the initiative of enterprises to adopt BIM also increases, and they tend to adopt strategies earlier. When the penalties $K=5,9$, the enterprise has a longer time to stabilize the strategy. At the same time, with the increasing awareness and enthusiasm of enterprises to adopt BIM technology, the government has achieved the purpose of promotion, and its strategy of adopting penalty measures to actively promote BIM technology has gradually turned to the strategy of passive promotion; that is, the game system is going to the stable point $\mathrm{B}(0,1)$ evolution. Therefore, judging from the simulation results, the necessary fines have a positive effect on enterprises' active adoption of BIM technology. The amount of government fines has little effect on the time to reduce their tendency to passive strategies, but companies are very sensitive, especially when the fine $K=20$. Companies will soon tend to actively adopt stable strategies in this case. Therefore, the government plays an active role in the diffusion of BIM technology, and the implementation of reasonable fines can effectively promote the adoption of BIM technology. In addition, the fines of government for enterprises should take into account the size of the 
enterprise, and the fines for extra large and large enterprises should be relatively high, which can be relatively reduced for small- and medium-sized enterprises, thereby enhancing the effectiveness of the fines.

(2) The sensitivity analysis of government and enterprises to subsidy management cost $C_{1}\left(C_{1}\right.$ is both the cost of the government and the benefit of the enterprise) is necessary because of the government's active initiative to promote BIM technology. The initiative of the government is an effective means for diffusing and developing new technology and also has a positive effect on the choice of enterprise strategy. Let $C_{1}=10,15,20$; the evolution of the BIM technology diffusion game system is shown in Figure 3.

It can be seen from Figure 3 that when $C_{1}=10,15$, 20 , the higher the government's subsidies to enterprises at this time, the higher the government's stability, and the sensitivity of enterprises to government subsidies is not high, the time for the three $C_{1}$ values to stabilize is basically the same, and the time is later, but in the end, the strategies of the government and enterprises have evolved to the stable point $\mathrm{B}(0,1)$. The government has to pay a certain amount of subsidies for enterprises. From the simulation results, with the increase of subsidies, the government will move toward a strategy of negative advancement earlier. Since BIM technology itself is a social technology system, enterprises adopt BIM technology; they not only consider the direct cost of BIM technology but also need to pay more attention to the indirect cost after adoption [41]. Government subsidies for enterprises are often a small part of the direct costs and do not include high indirect costs such as BIM talent training, BIM expert introduction, and BIM system operation and maintenance. Therefore, government subsidies will promote the active adoption of enterprises, but they cannot make enterprises. Soon, it will tend to a stable state. Therefore, the government's subsidies for enterprises are indispensable, which can increase the enthusiasm of enterprises to actively adopt BIM technology. The government should also consider the indirect costs after the enterprises adopt them and give them corresponding subsidies, which will greatly increase the effect of subsidies.

(3) The sensitivity analysis of government and enterprise on input cost $C_{2}$ : input cost is one of the important factors that affect the promotion of BIM technology diffusion by enterprises, and it is also the basis of government subsidies and incentives to promote voluntary adoption by enterprises. Let $C_{2}=15,10$, 30; the evolution of the BIM technology diffusion game system is shown in Figure 4.

As can be seen from Figure 4, the government and enterprises are highly sensitive to BIM technology

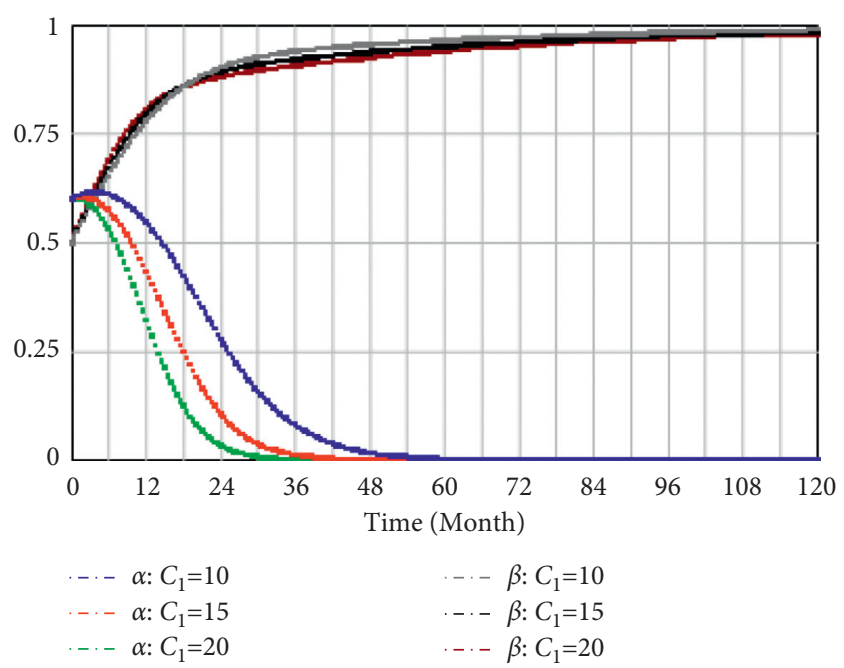

FIGURE 3: Government and enterprise sensitivity analysis of (C) value.

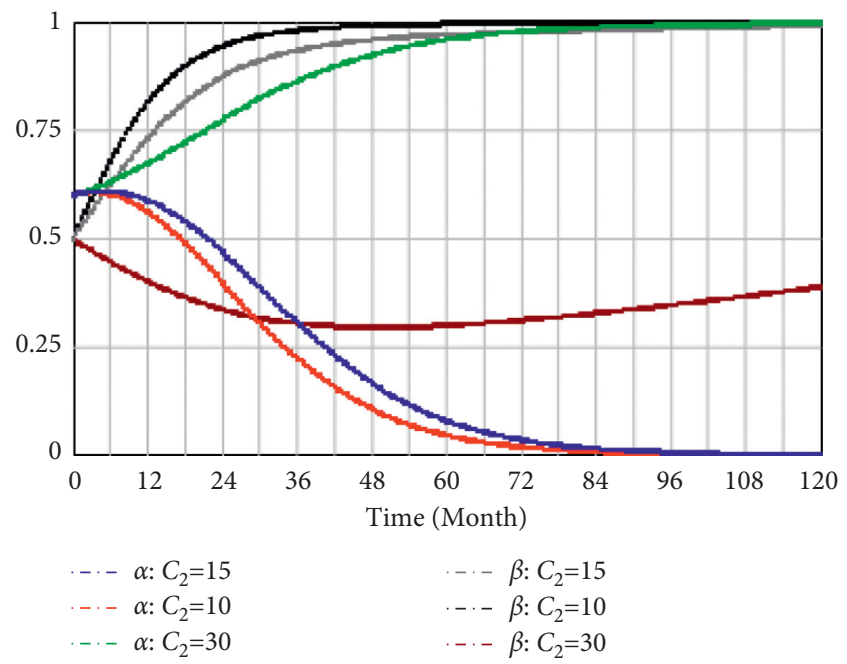

FIgURE 4: The sensitivity analysis of government and enterprises to $(\mathrm{C})_{2}$ value.

input costs. When the input cost is not high, the strategy of the government and enterprises chooses to evolve to the stable point $\mathrm{B}(0,1)$; when the input cost is high and the profit is not much different, the BIM technology diffusion game system goes to $\mathrm{D}(1,0)$ stable evolution and then to $C(1,1)$ stable evolution. The simulation results show that when $C_{2}=30$, the enterprise chooses a passive adoption strategy, and the government chooses an active promotion strategy to promote the diffusion of BIM technology; with the enhancement of the government's promotion role, the enterprise gradually evolves into an actively adopted strategy. In practice, the reason why enterprises adopt BIM technology is because of its high economic benefits. When the benefits are small and the cost is large, enterprises usually ignore it; however, the purpose of government to promote the diffusion of BIM 
technology is not only to promote economic benefits such as economic development and accelerating informatization construction but also to include ecological benefits such as environmental protection and resource conservation. When the cost of BIM technology is low, the enterprise itself can accept it, and the government often adopts a passive promotion strategy; once the cost of BIM technology is high when the enterprise refuses to adopt it, the government will adopt a series of positive strategies to encourage enterprises to adopt BIM technology. Therefore, when promoting the diffusion of BIM technology, enterprises should actively understand the successful cases of applying BIM to avoid a large number of controllable costs when applying BIM technology, so as to obtain higher profits, and enterprises will also promote BIM technology more actively. The research and development of BIM technology should be increased, and the improvement of BIM standards and specifications should be accelerated to reduce the cost and efficiency of enterprise applications and promote the diffusion of BIM technology.

(4) The sensitivity analysis of the government and enterprises to the input income $\mathrm{B}$ : the income from investing in BIM technology is the second important factor that affects the diffusion of BIM technology, and it also affects the government's strategic choices. Let $B^{\prime}=35,20,50$; the evolution of the BIM technology diffusion game system is shown in Figure 5.

It can be seen from Figure 5 that the BIM technology diffusion game system has a high sensitivity to the BIM technology investment income. The strategy of government and enterprise tends to be stable point $\mathrm{B}(0,1)$ when the return on input is high; when the input income is low and the cost is not much different, the BIM technology diffusion game system goes to $\mathrm{D}(1,0)$ stable evolution and then to $\mathrm{C}$ $(1,1)$ stable evolution. Compared with Figure 4 , the input cost is higher and the input income is smaller. The strategic choices for the government and the enterprise are the same, and eventually, all evolve steadily toward $C(1,1)$. From the numerical simulation results, when $B^{\prime}=35,50$, the government and enterprises 'strategy selection rate is very high in a relatively short period of time, and the strategies of passive promotion and active adoption are evolved; when $B^{\prime}=20$, both the government and enterprises will evolve at a relatively slow pace to actively promote and passively adopt strategies. The government will reach a stable state much faster than enterprises. It can be seen from the prospect theory that when the prospects for the development of BIM technology are unknown or there are many uncertainties, decision-makers often adopt a conservative strategy, that is, a risk-avoidance strategy. Therefore, it will take a long time for companies to shift from the concept of lower returns to BIM technology to the concept of higher returns. As shown in Figure 5, it will take a long period for companies to reach a stable state. But when the enterprise reaches a stable state, the government and the enterprise will evolve to the stable point $\mathrm{B}(0,1)$. In order to avoid the above situation, the

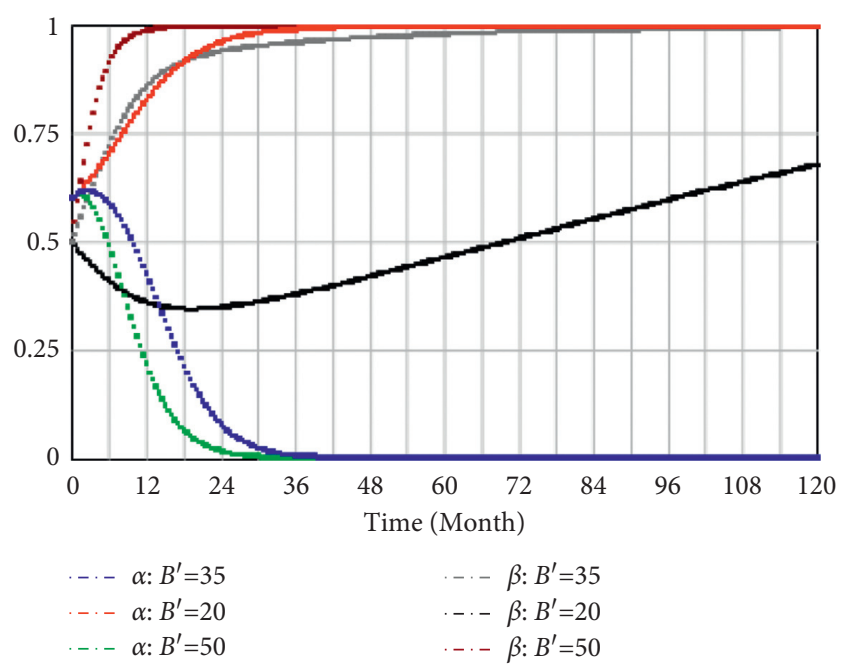

Figure 5: The sensitivity analysis of government and enterprises to $(\mathrm{B})^{\prime}$ value.

government should actively do BIM publicity work, training work, incentive work, subsidy work, etc., and companies should also strengthen the understanding and learning of BIM, conduct BIM seminars and exchanges, at the same time, make a clear definition of the high investment cost of BIM technology, and do a financial impact analysis.

\section{Conclusions and Recommendations}

BIM technology diffusion evolution game model is constructed and system dynamics software simulation analysis is carried out in this paper. The research shows that the two most sensitive factors of BIM technology diffusion are input income and input cost. The government's penalty on enterprises has a positive impact on the diffusion of BIM technology, while the subsidy cannot promote the effective diffusion of BIM technology among enterprises quickly. The game system eventually evolves to the stable point $(0,1)$, when the time for the government to reach the stable strategy is shortened.

Based on the above research results, the following suggestions are proposed to improve the diffusion level of BIM technology in China:

(1) The subsidy should pay more attention to the indirect costs after the adoption of BIM. While providing direct cost subsidies to adopting enterprises, the government should also pay attention to indirect costs such as talent training, expert introduction, and system maintenance that enterprises need to pay after adopting BIM technology; at the same time, they should take the lead in organizing BIM technology and management personnel training to ensure the successful application of BIM. The project will issue bonuses and certificates to accelerate the adoption and application of BIM technology by enterprises.

(2) Improving the punishment mechanism and highlighting the pertinence of punishment: in the slow 
stage of the proliferation of BIM technology, the government should improve the penalty mechanism as soon as possible to distinguish between enterprises of different sizes; the scope of mandatory application of BIM technology is not limited to large public buildings but should also be applied to residential buildings and industrial buildings. The government should make corresponding regulations and requirements, set up corresponding punishment regulations, and promote the proliferation of BIM technology.

(3) Clarifying the definition of high BIM investment cost and doing a good job of financial impact analysis: enterprises should have a clear understanding of the high investment cost of BIM technology, make clear definitions, and do a good job of financial analysis, so as to increase the willingness and enthusiasm of enterprises to adopt BIM technology.

\section{Data Availability}

The data are generated from experiments and can be available upon request to the author.

\section{Conflicts of Interest}

The author declares that there are no conflicts of interest.

\section{References}

[1] E. Alreshidi, M. Mourshed, and Y. Rezgui, "Requirements for cloud-based BIM governance solutions to facilitate team collaboration in construction projects," Requirements Engineering, vol. 23, no. 1, pp. 1-31, 2018.

[2] H. Xiao and H. Wang, "Asymmetric evolutionary game study on low-carbon environmentally friendly technological innovation diffusion," China Science and Technology Forum, vol. 8, pp. 20-27, 2017.

[3] Z. Liu, G. Pu, Y. Shi, J. Yan, and J. Hu, "Simulation analysis and evaluation of carbon emission reduction scenarios in the iron and steel industry," China Population, Resources and Environment, vol. 22, no. 3, pp. 77-81, 2012.

[4] M. Rogers Everett, Diffusion of Innovations, vol. 12, New York, US, 1995.

[5] V. Singh and J. Holmström, "Needs and technology adoption: observation from BIM experience," Engineering Construction and Architectural Management, vol. 22, no. 2, pp. 128-150, 2015.

[6] Y. Chen, K. D. Ruikar, and P. M. Carrillo, "Strategic ebusiness framework: a holistic approach for organisations in the construction industry," Journal of Information Technology in Construction, vol. 18, pp. 306-320, 2013.

[7] P. Grover, A. K. Kar, and M. Janssen, "Diffusion of blockchain technology," Journal of Enterprise Information Management, vol. 32, 2019.

[8] Y. Le, X. Zheng, Y. Li, Y. Lu, and J. Bai, "Research on application value stream and driving path of BIM technology based on SVN," Journal of Management in Engineering, vol. 32, no. 1, pp. 71-78, 2018.

[9] J. Cao, X. Wu, G. Zhou, and Q. Hu, "Game analysis in the process of green product innovation and diffusion in manufacturing enterprises," Journal of Systems Engineering, vol. 27, no. 5, pp. 617-625, 2012.

[10] T. Frohwein and B. Hansjürgens, "Chemicals regulation and the porter hypothesis - a critical review of the new European chemical regulation," Journal of Business Chemistry, vol. 2, no. 1, pp. 19-36, 2005.

[11] V. Peansupap and D. H. T. Walker, "Factors enabling information and communication technology diffusion and actual implementation in construction organizations," Journal of Information Technology in Construction, vol. 10, no. 14, pp. 193-218, 2005.

[12] V. Peansupap and D. H. T. Walker, "Innovation diffusion at the implementation stage of a construction project: a case study of information communication technology," Construction Management \& Economics, vol. 24, no. 3, pp. 321332, 2006.

[13] K. Panuwatwanich and R. A. Stewart, "Evaluating innovation diffusion readiness among architectural and engineering design firms: empirical evidence from Australia," Automation in Construction, vol. 27, pp. 50-59, 2012.

[14] C. Merschbrock and B. E. Munkvold, "Effective digital collaboration in the construction industry - a case study of BIM deployment in a hospital construction project," Computers in Industry, vol. 73, pp. 1-7, 2015.

[15] J. Ma, X. Li, J. Wang et al., "Experimental study on vibration reduction technology of hole-by-hole presplitting blasting," Geofluids, vol. 18, 2021.

[16] C. E. Laciana and S. L. Rovere, "Ising-like agent-based technology diffusion model: adoption patterns vs. seeding strategies," Physica A: Statistical Mechanics and its Applications, vol. 390, no. 6, pp. 1139-1149, 2011.

[17] P. Wang, G. Wang, and D. Tan, "Research on the diffusion and application obstacles of BIM technology," Construction Economy, vol. 39, no. 4, pp. 12-16, 2018.

[18] B. Sun, X. Su, and X. Xu, "Research on technology diffusion and evolution based on new technology adoption decision game," Industrial Technology and Economics, vol. 38, no. 6, pp. 10-19, 2019.

[19] C. Mark, "An updated empirical model for ground control in U.S. multiseam coal mines," International Journal of Mining Science and Technology, vol. 31, no. 02, pp. 163-174, 2021.

[20] H. Rafezi and F. Hassani, "Drilling signals analysis for tricone bit condition monitoring," International Journal of Mining Science and Technology, vol. 31, no. 02, pp. 187-195, 2021.

[21] X. Liu, S. Song, Y. Tan et al., "Similar simulation study on the deformation and failure of surrounding rock of a large section chamber group under dynamic loading[J]," International Journal of Mining Science and Technology, vol. 31, no. 3, pp. 495-505, 2021a.

[22] X. Liu, D. Fan, Y. Tan et al., "New detecting method on the connecting fractured zone above the coal face and a case study [J]," Rock Mechanics and Rock Engineering, vol. 54, $2021 \mathrm{~b}$.

[23] X. Liu, D. Fan, Y. Tan et al., "Failure evolution and instability mechanism of surrounding rock for close-distance parallel chambers with super-large section in deep coal mines[J]," International Journal of Geomechanics, vol. 21, no. 5, Article ID 04021049, 2021c.

[24] J. Wang, T. Zuo, X. Li, Z. Tao, and J. Ma, "Study on the fractal characteristics of the pomegranate biotite schist under impact loading," Geofluids, vol. 21, 2021.

[25] K. Ranjan, P. K. Mandal, A. Narayan, and A. Jyoti Das, "Evaluation of load transfer mechanism under axial loads in a novel coupler of dual height rock bolts," International Journal of Mining Science and Technology, vol. 31, no. 02, pp. 225-232, 2021. 
[26] J. Yang, H. Lian, and L. Li, "Investigating the effect of confining pressure on fracture toughness of CO2-saturated coals," Engineering Fracture Mechanics, vol. 242, no. 6266, Article ID 107496, 2020.

[27] J. Yang, H. Lian, and V. P. Nugyen, "Study of mixed mode I/II cohesive zone models of different rank coals," Engineering Fracture Mechanics, vol. 246, Article ID 107611, 2021.

[28] W. Hou, H. Wang, L. Yuan, W. Wang, X. Yang, and Z. Ma, "Experimental researchinto the effect of gas pressure, particle size and nozzle area on initial gas-release energy during gas desorption," International Journal of Mining Science and Technology, vol. 31, no. 02, pp. 253-263, 2021.

[29] W. Tang, Z. Cheng, J. Xu, Y. Sun, Y. Cong, and Y. Zheng, "The influence of borehole arrangement of soundless cracking demolition agents(SCDAs) on weakening the hard rock," International Journal of Mining Science and Technology, vol. 31, no. 02, pp. 197-207, 2021.

[30] Y. Zhou, D. Zhao, B. Li, Q. Tang, and Z. Zhang, "Fatigue damage mechanism and deformation behaviour of granite under ultrahigh-frequency cyclic loading conditions," Rock Mechanics and Rock Engineering, vol. 54, pp. 4723-4739, 2021.

[31] R. Guan, "The ministry of housing and urban-rural development issued the "guiding opinions on promoting the application of building information models", Construction Workers, vol. 36, no. 8, p. 50, 2015.

[32] K. Kang, Theory and Model of Technological Innovation Diffusion, Tianjin University Press, Tianjin, China, 2004.

[33] Y. Ma, X. Su, and Y. Zhao, "Evolutionary game analysis of industrial common technology diffusion," Control Theory \& Applications, vol. 36, no. 1, pp. 22-31, 2019.

[34] G. Heutel, "Prospect theory and energy efficiency," Journal of Environmental Economics and Management, vol. 96, pp. 236-254, 2019.

[35] $\mathrm{Li} \mathrm{Yu}, \mathrm{B}$. Wu, and C. Wang, "Evolutionary game analysis of behavior decision of crowdsourcing logistics distributor based on prospect theory--based on the perspective of shipper," Operations Research and Management, vol. 6, pp. 129-135, 2019.

[36] R. Fan, Game Theory, Wuhan University Press, Wuhan, China, 2011.

[37] D. Friedman, "On economic applications of evolutionary game theory," Journal of Evolutionary Economics, vol. 8, no. 1, pp. 15-43, 1998.

[38] Y. Hu and Q. Shen, "A system dynamics study on the development of Hong Kong housing industry," System Engineering Theory and Practice, vol. 7, pp. 32-37, 2001.

[39] Y. Yuan, Y. Tian, and J. Sun, "System dynamics modeling and simulation of the stability of industry-university-research technology alliance," Science Science and Technology Management, vol. 34, no. 4, pp. 3-9, 2013.

[40] K. Li, Y. Zhang, G. Jin, S. Yuebin, and X. Ge, "System dynamics analysis of high-speed rail operation safety supervision game evolution," Journal of Southwest Jiaotong University, vol. 54, no. 3, pp. 579-586, 2019.

[41] P. E. D. Love, I. Simpson, A. Hill, and C. Standing, "From justification to evaluation: building information modeling for asset owners," Automation in Construction, vol. 35, pp. 208-216, 2013. 